\title{
Factors affecting success of intrauterine insemination: a 3 year prospective study
}

\author{
Jayakrishnan K., Sneha Ann Abraham*, Divya Nambiar
}

\begin{abstract}
Department of Reproductive medicine, Obstetrics and gynaecology, KJK Hospital, Fertility Research and Gynaec centre, Nalanchira, Trivandrum 15, Kerala, India
\end{abstract}

Received: 27 January 2016

Accepted: 01 March 2016

\section{*Correspondence:}

Dr. Sneha Ann Abraham,

E-mail: snehaliju@gmail.com

Copyright: () the author(s), publisher and licensee Medip Academy. This is an open-access article distributed under the terms of the Creative Commons Attribution Non-Commercial License, which permits unrestricted non-commercial use, distribution, and reproduction in any medium, provided the original work is properly cited.

\begin{abstract}
Background: Intrauterine insemination (IUI) is the therapeutic process of placing washed spermatozoa transcervically into the uterine cavity for the treatment of infertility. The aim of this study is to analyze the variables that contribute to the success of stimulated IUI cycles. A prospective study was done to identify the most important parameters with regard to IUI success that would provide important data for predicting the success of therapy and further help in planning sub fertility treatment for couples.

Methods: This prospective analytical study was done at KJK Fertility Research and Gynaec Centre, Thiruvananthapuram, Kerala over a period of 3 years from June 2012 to June 2015 in 3851 stimulated IUI cycles.

Results: The overall pregnancy rate was $15.2 \%$. Among the predictive factors evaluated, the infertility diagnosis (PCO and male factor, $p$ value $<0.001$ ), the post wash semen count $(5-10$ million, $p$ value $<0.001)$, type of IUI (double IUI over single IUI, $p$ value $<0.001)$ and the endometrial thickness on the day of trigger $(9-10 \mathrm{~mm}, \chi 2=551.59 \mathrm{df}=5$ $\mathrm{p}<0.001)$ significantly influenced the pregnancy rate.

Conclusions: IUI is a successful contemporary treatment for appropriately selected cases of PCO and male factor infertility, especially when female age is $<35$ years.
\end{abstract}

Keywords: IUI, Post wash sperm count, Endometrial thickness, PCO, Male factor

\section{INTRODUCTION}

Intrauterine insemination (IUI) is the therapeutic process of placing washed spermatozoa transcervically into the uterine cavity for the treatment of infertility. IUI theoretically allows a relatively higher number of motile spermatozoa to reach the oocyte and it has been used for a variety of indications such as non-severe male factor infertility, unexplained infertility, cervical mucus hostility, ovulatory disturbances, mild endometriosis, antisperm antibodies and male sexual dysfunctions like impotency, hypospadias, and retrograde ejaculation. ${ }^{1-4}$ The rationale behind IUI is increasing the gamete density at the time and site of potential fertilization i.e., increasing the chances of spermatozoa meeting the oocyte in the fallopian tube after ovulation has occurred. IUI is generally considered as an intermediate step of low to moderate complexity before the application of more sophisticated assisted reproductive technologies (ART) such as IVF with or without ICSI.

The overall success rates of IUI remains controversial and depends on several factors, with published pregnancy rates varying from as low as 5\% to as high as $70 \%$ per patient, however a $10 \%-20 \%$ clinical pregnancies per cycle is an acceptable range for all aetiologies. ${ }^{2}$ The pregnancy rates per IUI cycle are quite variable in the literature due to differences in cause and duration of infertility, type of ovarian stimulation, sperm preparation techniques, treatment cycles and number of times IUI is performed during a cycle (single or double).

Several prognostic factors with regards to IUI treatment outcome have been identified, and include factors such as 
patient profile, duration of infertility, type of infertility, stimulation protocol, follicular response, endometrial thickness, timing and number of IUI, percentage of sperm with normal morphology, type and percentage of sperm ${ }_{7}^{\text {motility and total number of motile sperms inseminated. }}{ }^{3-}$

The aim of this study is to analyse the variables that contribute to the success of stimulated intrauterine cycles. A prospective study was done to identify the most important parameters with regard to IUI success that would provide important data for predicting the success of therapy and further help in planning sub fertility treatment for the couples. We postulate that IUI success is dependent on a combination of optimum endometrial milieu, successful ovulation with precise timing of insemination.

\section{METHODS}

\section{Subjects}

This prospective analytical study was done at KJK Fertility Research and Gynaec Centre, Thiruvananthapuram, Kerala over a period of 3 years from June 2012 to June 2015.

\section{Inclusion criteria}

The study group consisted of couples undergoing therapeutic IUI for the treatment of unexplained infertility, mild oligospermia (10-15 million sperms /ml), anovulation, minimal and mild endometriosis and sexual dysfunction. Tubes were assumed to be normal if there was no history suggestive of tubal pathology.

Exclusion criteria included those patients with bilateral tubal blockage, moderate to severe endometriosis and severe male factor infertility, with post wash sperm count of $<1$ million.

For couples fulfilling inclusion criteria, we registered maternal age, diagnosis, the number of pre-ovulatory follicles, type of controlled ovarian hyper stimulation, endometrial thickness, cycle number, type of IUI (single or double) and post wash sperm count.

Male factor infertility was defined as semen concentration $<15$ million sperms $/ \mathrm{ml}$, normal morphology $<4 \%$ (WHO criteria) and progressive motility $<32 \%(\mathrm{~A}+\mathrm{B})$ before sperm preparation as per the WHO (2010) guidelines. ${ }^{8}$

Unexplained infertility was defined as couples for whom the results of a standard infertility evaluation are normal (standard tests includes a normal semen analysis [WHO 2010], ovulatory cycles and a HSG or laparoscopy showing patent tubes).
Minimal endometriosis: score 1-5; mild endometriosis: score $6-15$ by the revised AFS criteria.

Poly cystic ovarian disease (PCOS) was diagnosed using the Rotterdam criteria (two out of the three): oligoovulation or anovulation, clinical and/ or biochemical evidence of hyper and organism with ultrasonic evidence of multiple small follicles of less than or equal to $10 \mathrm{~mm}$ diameter.

\section{Ovarian stimulation}

Couples with unexplained infertility, mild oligospermia, minimal to mild endometriosis and polycystic ovaries who failed to conceive after trying ovulation induction with timed intercourse for 6 cycles were counselled for IUI. The protocol for ovulation induction started with the first line drug, Clomiphene citrate (50-100mg $1 \mathrm{HS}$ x 5 days, Day 3 to Day 7). If the patient had already undergone ovulation induction with Clomiphene citrate for a maximum of 6 cycles or if the patient failed to achieve ovulation with Clomiphene citrate, then ovulation induction was performed with gona dotrophins, either $\mathrm{HMG}$ in non-PCO patients or $\mathrm{FSH}$ in $\mathrm{PCO}$ patients. A maximum of 4 cycles of IUI were performed and if the patient failed to conceive, the couple were counselled to the next line of management either laparoscopy or ART. For couples who were unable to progress to the next line of management after 4 cycles due to financial constraints or personal reasons, a maximum of 6 cycles of IUI were done.

In cycles stimulated with gonadotrophins, inj. hMG 75 IU (Menodac, Bayer Zydus Pharma Pvt Ltd) or inj FSH 50 IU or 75 IU (Fostine, Bayer Zydus Pharma Pvt Ltd)was administered on a daily basis from day 3 to day 7 . On day 8 of stimulation, assessment of follicular development was performed using transvaginal ultrasound. Further stimulation with gonadotrophin was determined according to follicular response. The aim of stimulation was to achieve a multifollicular ( 2 or 3 follicles) response. Once a follicle of $>17 \mathrm{~mm}$ size was identified, inj. human chorionic gonadotrophin 5000 IU (hCG) (Inj. Ovidac, Bayer Zydus Pharma Pvt Ltd) was given as an ovulation trigger and a single IUI $36 \mathrm{~h}$ later or a double IUI, 10-12 hours prior to ovulation and 8-10 hours after ovulation was planned. Single IUI was done for selected group of patients with moderate oligoasthenospermia (510 million sperms/ml) who had financial constraints and insisted on undergoing IUI for a few cycles.

If four or more mature follicles $(>17 \mathrm{~mm})$ developed, the cycle was cancelled.

\section{Semen preparation}

On the day of IUI, the husband was instructed to give semen that was prepared by the swim up technique or double-density gradient method with Nutrient Mixture F10 Ham (Sigma Aldrich, USA). The post wash sample 
parameters were assessed. Under aseptic precautions, IUI was carried out with a soft IUI catheter (Transperm Catheter; SAR Healthcare Ltd, India) with an insemination volume of $0.5 \mathrm{ml}$. After the procedure, the patient was advised 20 minutes of bed rest. All women were provided luteal phase support with natural micronized progesterone vaginal pessary for 10 days.

If menstrual cycle was delayed, urine pregnancy test was carried out. When positive, a transvaginal ultrasound was performed 2 weeks later to confirm a clinical pregnancy.

The primary end point of this study was a positive urine pregnancy test.

\section{Statistical analysis}

The variables selected were: patient parameters like age of woman and cause of infertility; parameters related to ovulation induction such as drugs used for $\mathrm{COH}$, number of dominant follicles and endometrial thickness and laboratory parameters such as post wash sperm count and type of IUI (whether single or double IUI).

Of these parameters, age of the woman was recorded as continuous variable, and their means were compared using the independent $t$-test. Other parameters were taken as categorical variables and were compared for significant differences using the Chi-square test.

A P-value of $<0.05$ was considered to be significant. Data were entered in SPSS version 17 (SPSS Inc., Chicago, IL, USA).

\section{RESULTS}

We evaluated a total of 3851 stimulated IUI cycles between June 2012 and June 2015.The mean female age was $29.4 \pm 4.5$ years (range, 20-44 years).

Table 1: Factors affecting pregnancy rates in intrauterine insemination.

\begin{tabular}{|lccccc|}
\hline & N & Mini & Max & Mean & $\begin{array}{l}\text { Standard } \\
\text { deviation }\end{array}$ \\
\hline $\begin{array}{l}\text { Age of } \\
\text { female }\end{array}$ & 3851 & 20 & 47 & 29.7 & 4.9 \\
\hline $\begin{array}{l}\text { Number } \\
\text { of } \\
\text { dominant } \\
\text { follicle }\end{array}$ & 3851 & 1 & 8 & 1.6 & 1.1 \\
\hline $\begin{array}{l}\text { IUI cycle } \\
\text { number }\end{array}$ & 3851 & 1 & 6 & 2.3 & 1.4 \\
\hline
\end{tabular}

Of the $3851 \mathrm{COH} / \mathrm{IUI}$ cycles analysed, 1474 were first treatment cycle, 999 were second treatment cycle, 667 were third treatment cycle and 413 were fourth treatment cycle, 165 were fifth treatment cycle and 133 were sixth treatment cycle during the study period.

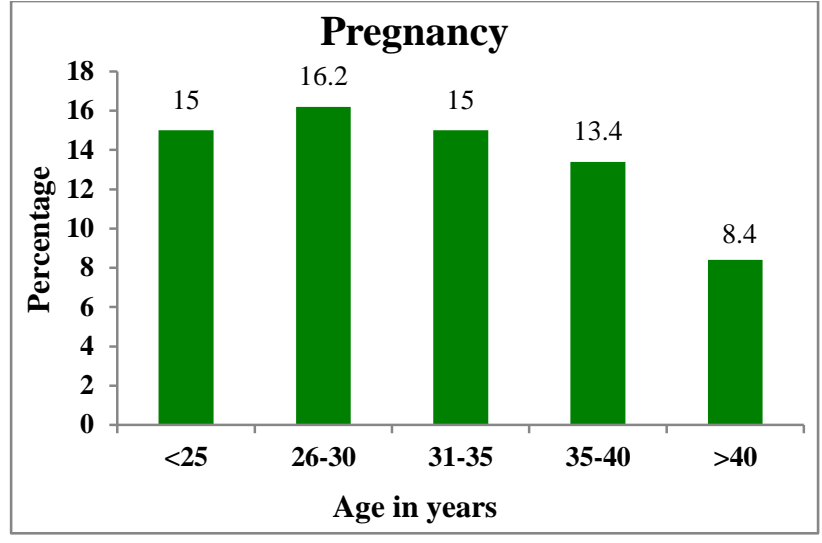

Chi square $=4.506$, Degree of freedom $=3$, $p$-value $=0.212$

Figure 1: Bar chart showing relationship between age of the patient and pregnancy rates.

Age $>40 y r$ has a negative impact on the success of IUI.

Cause of infertility was male factor in $31.1 \%$, an ovulatory in $25.1 \%$, endometriosis in $10.4 \%$, unexplained in $19.4 \%$ and other causes like social factors, coital problems in $14 \%$ of the patients.

We obtained a pregnancy rate of $15.2 \%$.

Table 2: Factors affecting pregnancy rates in intrauterine insemination.

\begin{tabular}{|llll|}
\hline Parameters & $\begin{array}{c}\text { Pregnancies } \\
\text { /cycle }\end{array}$ & $\begin{array}{l}\text { Pregnancy } \\
\%\end{array}$ & $\begin{array}{l}\text { P } \\
\text { values }\end{array}$ \\
\hline \multicolumn{4}{|c|}{ Infertility diagnosis } \\
\hline PCO & $195 / 967$ & 20.2 & \\
Unexplained & $112 / 747$ & 15 & $<0.001$ \\
Endometriosis & $32 / 400$ & 8 & \\
Male factor & $210 / 1197$ & 17.5 & \\
Other & $35 / 540$ & 6.5 & \\
\hline Post wash sperm count & & \\
\hline$<5$ million/ml & $129 / 1202$ & 10.7 & \\
5 -10 million/ml & $408 / 2180$ & 18.7 & \\
$>10$ million/ml & $47 / 469$ & 10 & $<0.001$ \\
\hline Type of IUI & & & \\
\hline Single IUI & $20 / 271$ & 7.4 & \\
Double IUI & $564 / 3580$ & 15.8 & \\
\hline Endometrial thickness in millimetres & \\
\hline$<7$ mm & $54 / 1486$ & 3.6 & \\
$7.1-8$ mm & $71 / 866$ & 8.2 & \\
$8.1-9 m m$ & $144 / 640$ & 21.5 & \\
$9.1-10$ mm & $180 / 434$ & 41.5 & \\
$10.1-14$ mm & $135 / 395$ & 34.2 & \\
\hline
\end{tabular}

Among indications for IUI, the success rates was higher among PCO and male factor infertility compared to other etiologies $(\mathrm{p}=<0.001)$ (Table 2$)$.

Post wash sperm count of 5-10 million during IUI significantly increases the success rate. $(p=<0.001)$ (Table 2). 
There was significant difference regarding pregnancy rates between single 24th hour and double 12th- and 36th-hour inseminations (Table 2).

The success rate of IUI is significantly increased between endometrial thicknesses $9 \mathrm{~mm}-10 \mathrm{~mm}$. Endometrial thickness on the day of hCG administration was significantly greater in cycles where pregnancy was achieved (Table 2).

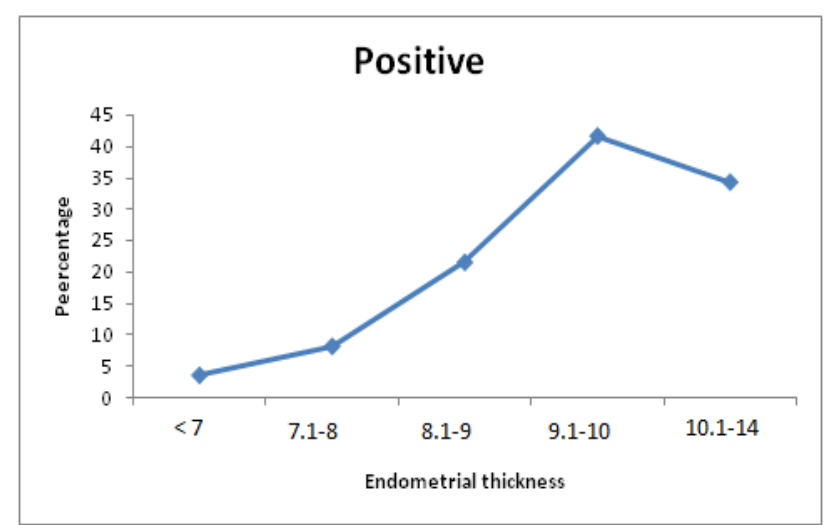

Chi square $=551.59$, Degree of freedom $=5, \mathrm{p}$-value $<0.001$

Figure 2: Line diagram showing the relationship between endometrial thickness in millimetres and pregnancy rates in percentages.

The protocol used for stimulation of ovarian follicles did not affect the success of IUI. The protocols used for stimulation were Clomiphene citrate and Gonadotrophins.

Number of pre- ovulatory follicles and the IUI cycle number did not seem to affect the prognosis of IUI.

\section{DISCUSSION}

The study attempted to identify the important IUI variables with regard to successful outcome and to form a model for success from which the outcomes of subsequent cycles could be more accurately predicted. The variables studied include factors such as patient profile, cause of infertility, stimulation protocol, follicular response, endometrial thickness, timing and number of IUI, and lab parameters like post wash sperm count.

Our analysis found four significant variables: Endometrial thickness, post wash sperm count, performance of a double IUI over single IUI and $\mathrm{PCO} /$ male factor as the infertility diagnosis.

\section{Age of patient}

Among the patient parameters, female age is important as declining oocyte quality associated with increasing age is well documented.9,10 Even more effective treatment options like ART-IVF cannot completely overcome the negative impact of age. ${ }^{11}$ In our study, a trend toward reduction in success rate with $\mathrm{COH} / \mathrm{IUI}$ was noted in women with age $>35$ years, although the difference was not statistically significant. Age $>40 \mathrm{yrs}$ had a negative impact on the success of IUI. This decline in success in probably due to a combination of progressive follicular depletion, decline in granulose function, poor oocyte quality, reduced endometrial receptivity, higher rate of chromosomal abnormalities and increase in frequency of an ovulatory cycles after age 40, ageing of the reproductive tract and diseases of the reproductive tract.

Many studies have documented a significant drop in the success rate beyond the age of 40 years, with reported live births being as low as $1.4 \% .{ }^{12-14}$ Put together, for women over $35, \mathrm{COH} / \mathrm{IUI}$ as a treatment option needs careful consideration, and for women over 40, IUI is a poor treatment option. On the other hand, in women of younger age group with no risk factors, IUI can be offered as a treatment option as it has $15 \%$ increased chances of pregnancy compared to natural methods of conception.

\section{Indications of IUI}

Among the indications for IUI, we found that the success rates were higher among PCO $(20.2 \%)$ and male factor infertility $(17.5 \%)$ compared to other etiologies $(\mathrm{p}=<0.001)$.

In study by Soria $\mathrm{M}$, et al the pregnancy rate per cycle for patients with anovulation due to PCOS was $13.3 \%$, confirming the significant relationship between this etiology and IUI outcomes. ${ }^{15}$ It seems clear that $\mathrm{COH}$ corrects ovulation and therefore, results in a high IUI success rate. Endometriosis, on the other hand, which is among the disorders that are the most difficult to treat, decreased the IUI success rate in our study to $8 \%$ per cycle. ${ }^{16}$ Similar results were obtained by Vlahos, et al who reported a pregnancy rate per cycle of $19.1 \%$ for cases with anovulation, compared to $9.1 \%$ for cases with endometriosis, and by Dickey, et al who also reported better results for cases with anovulation. ${ }^{17,18}$

So a short course of IUI of 3-4 cycles could result in conception in PCO and mild oligo zoospermia and should be offered to patients as it is a less expensive and technically less difficult procedure. Also in couples with unexplained infertility and minimal to mild endometriosis who cannot afford ART, a short course of IUI can be offered as it has slightly better chances over natural conception.

\section{Endometrial thickness}

The success rate of IUI was significantly increased between endometrial thicknesses 9mm-10mm. Endometrial thickness on the day of hCG administration was significantly greater in cycles where pregnancy was achieved. 
Correlation between endometrial thickness with pregnancy rate and predisposing factors for growth of endometrium are unclear. In our study we evaluated endometrial thickness within 5 ranges of $<7 \mathrm{~mm}, 7.1$ 8mm, 8.1 -9mm, 9.1 -10mm and $10.1-14 \mathrm{~mm}$. We found that pregnancy rates were maximum when the endometrial thickness was between 9-10mm $(p<0.001)$ though there is an increasing trend to positive pregnancy with endometrial thickness between $7 \mathrm{~mm}-14 \mathrm{~mm}$. The pregnancy rates were very low when IUI was done with endometrial thickness $<7 \mathrm{~mm}$. The aim should be to keep the endometrial thickness between 7-14 mm prior to IUI.

Reuter, et al concluded that endometrial thickness of at least $8 \mathrm{~mm}$ is correlated with higher rate of conception. ${ }^{19}$ In study by Ezmailzadeh, et al endometrial thickness on the day of hCG administration was significantly greater in cycles where pregnancy was achieved. ${ }^{20}$ Dickey, et al studied on relationship of endometrial thickness to fecundity in ovulation induction cycles and concluded that no pregnancy occurred when thickness was less than $6 \mathrm{~mm}$, but the continuing pregnancy rate was $12.6 \%$ when thickness was more than or equal to $9 \mathrm{~mm} .{ }^{21}$ Weissman, et al study observed a detrimental effect of increased endometrial thickness $>14 \mathrm{~mm}$ on pregnancy rates. ${ }^{22}$

\section{Post wash sperm count}

Post wash sperm count of 5-10 million during IUI was found to significantly increase the success rates $(p=<0.001)$. In our study, the majority of patients had a post wash count between 5-10 million and this could be one of the reasons why we obtained a statistical significance.

Sakhel, et al reported a direct relationship between sperm count and the pregnancy rate. ${ }^{23}$ Wainer, et al showed that a minimum of $5 \times 10^{6}$ motile spermatozoa should be inseminated when the normal morphology of the sperm after preparation is $<30 \% .^{24}$ Study by Miller, et al have demonstrated that the total motile sperm count independently predicts success of IUI and that cycles with less than 10 million total motile sperm are significantly less likely to result in a pregnancy. ${ }^{25}$ Study by Berg, et al says that strict analysis of motile sperm count after swim-up is a useful prognostic factor for pregnancy after IUI. $^{26}$ There is a good chance for conception if $\geq 0.8 \times 10^{6}$ motile sperm are available after appropriate selection methods. Intrauterine insemination performed with considerably higher numbers of motile sperm does not lead to a significant increase in pregnancy rates. Elvan Koyun Ok, et al have also found that post wash inseminated semen count significantly increases the pregnancy rates. $^{27}$

\section{Double vs single IUI}

The timing of insemination relative to ovulation is critical for an optimal success rate. There was significant difference regarding pregnancy rates between single $36^{\text {th }}$ hour and double $\left(18-24^{\text {th }}\right.$ hr and $36-48^{\text {th }}$ hour) inseminations. The success rate was significantly better with double IUI. $(p=<0.001)$. But we had a higher number of patients in the category of double IUI and this could be the reason for statistical significance. Double IUIs have higher pregnancy rates in subfertile couples compared to single IUI. (Cochrane review 2010) ${ }^{28}$. Silerberg, et al and Ragni, et al found significantly more pregnancy rates in double IUI. ${ }^{29,30}$ Liu, et al in a randomised study reported a significantly higher pregnancy rate with double IUI for male factor infertility but no significant increase in couples with unexplained infertility. ${ }^{31}$

Increasing the number of inseminations improve the chance of conception because of the unsynchronised ovulation pattern in $\mathrm{COH}$ with multiple ovulations sequentially over more than 24 hours. Although first insemination would provide sufficient spermatozoa before the first released oocyte, the second insemination provide additional spermatozoa to fertilise oocytes likely to be released subsequently. Animal studies demonstrate that, $<10 \%$ of inseminated sperms are retained in the upper reproductive tract even 12 hours after IUI. This attrition phenomenon, along with observations showing a reduced sperm motility, further ads appeal to double IUI.

Number of pre-ovulatory follicles and the IUI cycle number did not seem to affect the prognosis of IUI in our study. Montanaro Gauci M, et al found that the number of follicles had a linear association with the risk ratio (chance) of pregnancy. ${ }^{32} \mathrm{~A}$ study by M Farimani, et al has found that a multifollicular response results in better treatment outcome than a monofollicular response. They also found that most pregnancies occur during a course of four IUI cycles.

Also our study failed to identify any advantage of gonadotrophins over oral ovulogens for ovulation induction. A Cochrane review was performed by Cantineau and Cohlen to evaluate different ovarian stimulation protocols (antiestrogens, aromatase inhibitors, and gonadotropins with or without $\mathrm{GnRH}$ agonists/antagonists) and the analysis revealed that gonadotropins, in low-dose regimens (50-75 IU), were the most effective agents when ovarian stimulation was combined with IUI. ${ }^{33}$ Although less effective than gonadotropins, antiestrogens were more cost effective in IUI therapy. ${ }^{34}$

\section{CONCLUSIONS}

IUI is a successful contemporary treatment for appropriately selected cases of PCO and male factor infertility, especially when female age is $<35$ years. The overall pregnancy rate per cycle with $\mathrm{COH} / \mathrm{IUI}$ in our study was $15.2 \%$.

Endometrial thickness between 7-14 mm, especially 9-10 $\mathrm{mm}$ at the time of hCG trigger, post wash sperm count of 
5-10 million and performance of double IUI is associated with increased pregnancy rates in IUI with $\mathrm{COH}$. It is a less expensive and less invasive technique compared to ART. Careful patient selection criteria coupled with ovarian stimulation appear to be the model for IUI success.

Funding: No funding sources

Conflict of interest: None declared

Ethical approval: The study was approved by the Institutional Ethics Committee

\section{REFERENCES}

1. Keck C, Gerber-Schafer C, Wilhelm C, Vogelgesang $\mathrm{D}$, Breckwoldt $\mathrm{M}$. Intrauterine insemination for treatment of male infertility, International Journal of Andrology. 1997;20:55-64.

2. Duran HE, Morshedi M, Kruger T, Oehninger S. Intrauterine insemination: A systematic review on determinants of success. Hum Reprod Update. 2002;8:373-84.

3. Guzick DS, Carson SA, Coutifaris C, Overstreet JW, Factor-Litvak P, Steinkampf MP. Efficacy of superovulation and intrauterine insemination in the treatment of infertility. N Engl J Med. 1999;340:17783.

4. Hughes EG. Stimulated intra-uterine insemination is not a natural choice for the treatment of unexplained subfertility: Effective treatment or 'not a natural choice'? Hum Reprod. 2003;18:912-4.

5. Van Rumste M, Custers I, van der Veen F, van Wely M, Evers J, Mol B. The influence of the number of follicles on pregnancy rates in intrauterine insemination with ovarian stimulation: A metaanalysis. Hum Reprod Update. 2008;14:563-70.

6. Wainer R, Albert M, Dorion A, Bailly M, Bergere $\mathrm{M}$, Lombroso R. Influence of the number of motile spermatozoa inseminated and of their morphology on the success of intrauterine insemination. Hum Reprod. 2004;19:2060-5.

7. Tomlinson M, Amissah-Arthur J, Thompson K, Kasraie J, Bentick B. Infertility: Prognostic indicators for intrauterine insemination (IUI): Statistical model for IUI success. Hum Reprod. 1996;11:1892-6.

8. World Health Organization, Department of Reproductive Health and Research. WHO laboratory manual for the examination and processing of human semen. Switzerland: WHO Press. 2010.

9. Baird DT, Collins J, Egozcue J, Evers LH, Gianaroli L, Leridon H. Fertility and ageing. Hum Reprod Update. 2005;11:261-76.

10. Grondahl M, Andersen YC, Bogstad J, Nielsen F, Meinertz H, Borup R. Gene expression profiles of single human mature oocytes in relation to age. Hum Reprod. 2010;25:957-68.

11. Leridon H. Can assisted reproduction technology compensate for the natural decline in fertility with age? A model assessment. Hum Reprod. 2004;19:1548-53.

12. Dickey RP, Taylor SN, Lu PY, Sartor BM, Rye PH, Pyrzak R. Effect of diagnosis, age, sperm quality, and number of pre ovulatory follicles on the outcome of multiple cycles of clomiphene citrate-intrauterine insemination. Fertil Steril. 2002;78:1088-95.

13. Agrawal SK, Buyalon RP. Clomiphene citrate with intrauterine insemination. Is it effective therapy in women above the age of 35years? Fertil Steril. 1996;65:759-63.

14. Frederick J, Denker M, Rojas A, Horta I, Stone S, Asch R. Infertility: Is there a role for ovarian stimulation and intra-uterine insemination after age 40? Hum Reprod. 1994;9:2284-6.

15. Soria M, Pradillo G, García J, Ramón P, Castillo A, Jordana C. Pregnancy Predictors after Intrauterine Insemination: Analysis of 3012 Cycles in 1201 Couples. J Reprod Infertil. 2012;13(3):158-66.

16. Härkki P, Tiitinen A, Ylikorkala O. Endometriosis and assisted reproduction techniques. Ann N Y Acad Sci. 2010;1205:207-13.

17. Vlahos NF, Coker L, Lawler C, Zhao Y, Bankowski B, Wallach EE. Women with ovulatory dysfunction undergoing ovarian stimulation with clomiphene citrate for intrauterine insemination may benefit from administration of human chorionic gonadotropin. Fertil Steril. 2005;83(5):1510-6.

18. Dickey RP, Taylor SN, Lu PY, Sartor BM, Rye PH, Pyrzak R. Effect of diagnosis, age, sperm quality, and number of pre ovulatory follicles on the outcome of multiple cycles of clomiphene citrate intrauterine insemination. Fertil Steril. 2002;78(5):1088-95.

19. Reuter H, Cohen S, Fureg C, Baker S. sonographic appearance of the endometrium and ovaries during cycles stimulated with human menopausal gonadotropin. J Reprod Med. 1996;41:509-14.

20. Esmailzadeh S. Endometrial thickness and pregnancy outcome after IUI. Fertility Steril. 2007;88:432-7.

21. Dickey RP, Olar TT, Taylor SN, Curok DN, Matulich EM. Relationship of endometrial thickness and pattern to fecundity in ovulation induction cycles: ffect of cc alone and with HMG. Fertil Steril. 1993;59:756-60 .

22. Weissman A-Gotlieb L, Casper RF. The detrimental effect of increased endometrial thickness on implantation and pregnancy rates. Fertil Steril. 1999;71:147-9.

23. Sakhel K, Abozaid T, Schwark S, Ashraf M, Abuzeid M. Semen parameters as determinants of success in 1662 cycles of intrauterine insemination after controlled ovarian hyperstimulation. Fertil Steril. 2005;84(1):S248-9.

24. Wainer R, Albert M, Dorion A. Influence of the number of motile spermatozoa inseminated and of their morphology on the success of intrauterine insemination, Human Reprod. 2004;19,9:2060-5.

25. Miller DC, Hollenbeck BK, Smith GD. Processed total motile sperm count correlates with pregnancy 
outcome after intrauterine insemination, Urology. 2002;60(3):497-501.

26. Berg U, Brucker C, Berg FD. Effect of motile sperm count after swim-up on outcome of intrauterine insemination, Fertility and Steril. 1997;67,4:747-50.

27. Koyun Ok E, Doğan OE, Okyay RE, Gülekli B. The effect of post-wash total progressive motile sperm count and semen volume on pregnancy outcomes in intrauterine insemination cycles: a retrospective study.J Turk Ger Gynecol Assoc. 2013;14(3):142-5.

28. Cantineau AEP, Heineman MJ, Cohlen BJ. Single versus double intrauterine insemination (IUI) in stimulated cycles for sub fertile couples. Cochrane Database of Systematic Reviews. 2003;1:CD003854.

29. Silverberg KM, Johnson JV, Olive DL, Burns WN, Schenken RS. A prospective, randomized trial comparing two different intrauterine insemination regimens in controlled ovarian hyper stimulation cycles. Fertil Steril. 1992;57:357-61.

30. Ragni G, Maggioni P, Guermandi E, Testa A, Baroni E, Colombo M. Efficacy of double intrauterine insemination in controlled ovarian hyperstimulation cycles. Fertil Steril. 1999;72:619-22.

31. Wei Liu, Fei Gong, Keli Luo, Guangxiu Lu. Comparing the pregnancy rates of one versus two intrauterine inseminations (IUIs) in male factor and idiopathic infertility. J Assist Reprod Genet. 2006;23(2):75-9.

32. Gauci MM, Kruger TF, Coetzee K, Smith K, Van Der Merwe JP, Lombard CJ. Stepwise regression analysis to study male and female factors impacting on pregnancy rate in an intrauterine insemination programme. Andrologia. 2001;33(3):135-41.

33. Cantineau AEP, Cohlen BJ. Ovarian stimulation protocols (anti-oestrogens, gonadotrophins with and without GnRH agonists/antagonists) for intrauterine insemination (IUI) in women with subfertility, The Cochrane Database of Systematic Reviews. 2007;2:1-135.

Cite this article as: Jayakrishnan K, Abraham SA, Nambiar D. Factors affecting success of intrauterine insemination: a 3 year prospective study. Int J Reprod Contracept Obstet Gynecol 2016;5:1077-83. 